\title{
AN EVOLUTIONARY GAME STUDY ON IMPLEMENTATION OF ENERGY EFFICIENCY POWER PLANTS BETWEEN GOVERNMENT AND ENTERPRISE CONSIDERING CARBON EMISSION RIGHT TRADING
}

\author{
ZHU, Y. P. ${ }^{1 *}-$ FENG, W. ${ }^{1}-$ FAN, L. Z. ${ }^{2}$ \\ ${ }^{1}$ Management School, Nanchang University, Nanchang, Jiangxi Province 330031, China \\ (e-mail:vivienne_fw@163.com-W.Feng) \\ ${ }^{2}$ Management School, Anhui University, Hefei, Anhui Province, 230601, China \\ (e-mail:843458904@qq.com) \\ *Corresponding author \\ e-mail:zhuyipingnet@ncu.edu.cn \\ (Received $13^{\text {th }}$ Sep 2018; accepted $28^{\text {th }}$ Nov 2018)
}

\begin{abstract}
EPP (energy efficiency power plant) is a kind of "virtual power plant", pointing to reduce power consumption and carbon emission by a series of energy-saving measures in a region. The benefits and strategies of government and enterprises influence the effect of implementing EPP, and game analysis is an effective method to analyze this matter. In this paper, an evolutionary game model between government and enterprise implementing EPP considering carbon emission right trading is built, and the model's stability and evolution paths are analyzed; then Matlab software is used to simulate the impact from sensitivity of some important parameters; at last a calculation example are carried out to analyze the influence on the game equilibrium from government's rewards and penalties, and a code by VC++ is programmed to achieve the solution of this case study. The results of sensitivity analysis and calculation example are consistent. Suggestion and advice are given respectively to optimize the outcome of the game in each part of above work. We hope the work in this paper is beneficial to formulate a reasonable guide mechanism of EPP, including good government policy orientation, enterprise implementing strategy and reasonable carbon trading strategy, so as to create a good development environment for EPP. Keywords: evolutionary game, energy efficiency, demand side management, suggestions, Matlab, vc++
\end{abstract}

\section{Introduction}

\section{Background}

Along with the accelerated process of industrialization and urbanization, a large amount of fossil energy has been consumed, which has caused enormous damage to the environment. The DSM (demand side management) aims to improve energy efficiency, save energy and reduce emissions and protect the environment. EPP (Energy efficiency power plant) is the latest form of DSM. Compared with decentralized demand-side management measures, EPPs have the characteristics of large scale, low financing cost and remarkable energy saving effect. The energy saving measures of EPP include green lighting, high-efficiency motors, frequency conversion governor, energysaving transformers, high-efficiency household appliances, refrigeration and heating equipment as well as interruptible load. Over the past 10 years, the development of EPP has achieved abundant energy conservation and emission reduction effects and formed a certain scale. For example, the State Grid Energy Research Institute of China counts that the generation capacity of EPP is 640.7 billion kWh in China of 2011-2015, and estimates 2016-2020 is 1.3254 trillion $\mathrm{kWh}$. It can reach 1.9661 trillion $\mathrm{kWh}$ during the 
period of 2010-2020, equivalent to a reduction of $22,598 \mathrm{kWh}$ in generation capacity and nearly 57 billion USD in investment compared with the conventional power plants (Du et al., 2015).

However, in the implementation process of EPP, enterprises believe that the implementation of EPP will lead to increased costs, and they are not enthusiastic about investing in EPP. The government lacks effective supervision means and incentive mechanism; Public awareness of EPP is not clear. Above problems seriously restrict the development of EPP. The reasons for the above problems lie in that the interests of the major participants are different from each other. If the interests of a single party are taken as the starting point, the optimal decision-making schemes of each party cannot be coordinated and unified, or even conflict, resulting in the failure of EPP implementation. Ultimately there is a lack of scientific game study on implementing EPP, which is also the problem to be solved in this paper.

\section{Literature review}

Thus to solve above problems, low carbon investment game analysis is a hot research topic. The game analysis in low carbon environment comes firstly from supply chain research. Du et al. (2015) conducted a game-theoretical analysis and Du et al. (2017) gave low-carbon supply policies for supply chain management. Li et al. (2017) examined the influences of different game structures on the optimal decisions and performance of a low-carbon closed-loop supply chain (CLSC) with price and carbon emission level dependent market demands. Liu et al. (2017) investigated the emission reduction performance for supply chain members in both single-channel and exclusive dual-channel cases. Other researches of supply chain focus on the low-carbon product selection (Meng et al., 2018; Xiao et al., 2018; He et al., 2018) carbon emission reduction (Wang et al., 2018; Zhou and Ye, 2018) and low-carbon strategies (Zu al., 2018)

Followed by the supply chain is the game analysis between participants in lowcarbon investment. Luo et al. (2016) developed a Stackelberg-like model i to gametheoretically analyze the decentralized decisions of the manufacturer and retailer. Gu et al. (2017) established the evolutionary game model between government and highway logistics enterprises. Wu et al. (2017) used game-based learning theory for reference and built an evolutionary model of low-carbon strategies based on the game between the government and enterprises in the context of a complex network. Zhao et al. (2017) developed the unit root test and the run test to analyze the carbon emission market of four representative cities in China. Chen et al. (2018) examined the role of co-opetition in low-carbon manufacturing.

While the above literatures do not specify what kind of low carbon behavior, so many literatures turn to discuss some kind of specific low-carbon objects, such as solar energy adoption (Varun and Ariane, 2017), low-carbon green oil port (Fan et al., 2012a, b). However, there is a lack of game study on implementing EPPs.

\section{Purpose of the study}

While the above researches of low-carbon investment generalizes low-carbon investment of enterprise into low-carbon production, low-carbon behavior, and energy conservation and emission reduction vaguely, but not into what kind of low-carbon behavior specifically, which cannot provide more specific game strategies. There are 
some literature mainly discussing the integrated resource planning (Zhu et al., 2017) and energy efficiency (Wang et al., 2015, 2016) of EPP, but we seldom find researches discussing game analysis about implementing EPP. As game analysis between the government and enterprises are the most important subject (Fan et al., 2017; Cao et al., 2016), thus the low-carbon investment to the implementation of EPP is specified, the evolutionary game model of government and enterprise under the background of implementing EPP is established, and the model's stability and evolution paths are analyzed by model derivation, Matlab software and vc++ programs.

\section{Materials and methods}

\section{Theoretical basis}

\section{Introduction to evolutionary game theory}

The combination of dynamic evolution and game analysis constitutes the basis of evolutionary game theory. Evolutionary game theory is based on the limited rationality of participants and it considers that the behavior adjustment of participants is a dynamic process (Ratul, 2012). The whole system is constantly moving to the equilibrium state. When there are multiple equilibrium systems, the equilibrium state of the system is realized, which is determined by the evolutionary path of the initial state and evolution of the system.

\section{Game behavior analysis of implementing EPP}

In low-carbon economy, the government is the main body to constraint the resources and environment, which gives guidance and adjustment for enterprise implementing EPP and gives supports from the aspects of laws, regulations and policies. Enterprises are the main body to implement EPP, so they should not only undertake the important task of saving electricity, reducing emissions and protecting the environment, but also take the responsibility for enhancing the competitiveness of their products and ensuring sustainable development of themselves. Because government and enterprises pursue different goals, there is a fierce game in the process of implementing EPP inevitably. Both sides need to adjust their own game strategy according to the other side's, so as to maximize the utility and reach the game equilibrium. Therefore, the best strategy to implement EPP must be the result of multiple games and rational choices between government and enterprises.

The purpose of constructing the game model of the government and enterprise implementing EPP is to help government adopt a reasonable guidance and management mechanism, and help enterprise adopt reasonable implementing measures, which will ultimately contribute to the development of the EPPs.

\section{Building of the evolutionary game model}

\section{Hypotheses}

(1) Participants in the game

The participants in this game are both local government and enterprises implementing EPP, and both have limited rational characteristics.

(2) Behavioral strategies 
The set of government's strategy is $\{\mathrm{H}-\mathrm{Strict}$ supervision, L-Lax regulation $\}$. "Strict supervision" refers to the strict implementation of carbon emission reduction policies by local governments, timely accounting for the carbon emission of enterprises and urging enterprises to comply with carbon emission reduction constraints, in this paper, the way is namely implementing EPP.

The set of enterprise's strategy is A-implementing EPP, N-not implementing EPP $\}$. "Implementing EPP" refers that enterprises chose to implement EPP to fulfill their duties of supervision and carbon accounting. "Not implementing EPP" refers that enterprises for some reasons do not choose to implement EPP and result in excessive emissions.

So this game contains four pure policy strategies combinations, namely $\{\mathrm{H}-\mathrm{Strict}$ supervision, A-implementing EPP $\},\{$ H-Strict supervision, N-not implementing EPP $\}$, $\{$ L-Lax regulation, A-implementing EPP $\}$ and $\{$ L-Lax regulation, N-not implementing EPP .

(3) Parameter assumptions and their implications

(1) Suppose the government allocated to the enterprise in a specific period of time of carbon emission quotas as $D$, at present $D$ is generally determined by historical average level of carbon emissions in carbon trading market, and free distribution is predominate. When the enterprise emissions are not excessive, the carbon emission is $D_{A}$. When the enterprise has excessive emissions, the carbon emission is $D_{N}$. Obviously $D_{A} \leq D \leq D_{N}$.

(2) The implementation of EPP can save power energy, assuming that the implementation cost of saving a unit $(\mathrm{kWh})$ power is $c_{0}$, the electric price per unit is $e$, and carbon emission reduction of unit power is $d$. Set $a=\left(e-c_{0}\right) / d$, then $a$ can be understood as the capacity benefit of unit carbon emission.

(3) Assume that the regulatory costs of strict supervision by local governments are $C_{g H}$, costs of lax supervision are $C_{g H}$, obviously $C_{g H} \geq C_{g L}$.

(4) Suppose that when enterprises' carbon emissions are within the quota, the government can gain profit $P_{g}$ from the emission reduction, which is related to the emission reduction quantity $D-D_{A}$, including the reduction of environmental damage caused by enterprise emission reduction, environmental improvement, and the increase of public satisfaction to the government. Enterprises can benefit $P_{c}$ from emissions cuts, associated with emission reduction $D-D_{A}$ by implementing EPPs, including social image and reputation improvement, and more government policy support.

(5) When enterprises carbon emissions are excess, the government will impose fines $F$ on enterprises, which is related to the excess emission $D_{N}-D$. The fines include both cash penalty and crackdown on those enterprises.

(6) Assumed that the excessive emissions of enterprises will also bring losses $V$ to local governments, related to the excess emission of enterprises. $V$ includes the damage to the environment by excessive carbon emissions from the enterprise, public dissatisfaction with the government due to environmental variation, and punishment from the higher level government.

Table 1 shows the above parameters and their definitions. 


$$
-703-
$$

Table 1. Main parameters in the model and their definitions

\begin{tabular}{c|c|c|c}
\hline Parameter & Definition & Parameter & Definition \\
\hline$D$ & Carbon emission allowances & $c_{0}$ & $\begin{array}{c}\text { EPP implementation cost of saving a unit } \\
\text { (kWh) power }\end{array}$ \\
\hline$D_{A}$ & $\begin{array}{c}\text { Carbon emission when enterprise } \\
\text { adopts strategy A }\end{array}$ & $e$ & Electric price per unit \\
\hline$D_{N}$ & $\begin{array}{c}\text { Carbon emission when enterprise } \\
\text { adopts strategy N }\end{array}$ & $d$ & $\begin{array}{c}\text { Carbon emission reduction per unit } \\
\text { power }\end{array}$ \\
\hline$C_{g H}$ & $\begin{array}{c}\text { Regulatory costs of strict } \\
\text { supervision }\end{array}$ & $P_{g}$ & $\begin{array}{c}\text { Profit of government when carbon } \\
\text { emissions are within the quota }\end{array}$ \\
\hline$C_{g L}$ & $\begin{array}{c}\text { Regulatory costs of lax } \\
\text { supervision }\end{array}$ & $P_{c}$ & $\begin{array}{c}\text { Profit of enterprise when carbon } \\
\text { emissions are within the quota }\end{array}$ \\
\hline$F$ & Fines on excessive carbon \\
emissions & $V$ & $\begin{array}{c}\text { Losses to local governments by excessive } \\
\text { emissions of enterprises }\end{array}$ \\
\hline
\end{tabular}

\section{The evolutionary game model}

Assuming carbon price $(p)$ per unit is an exogenous variable, determined by the market. When the carbon emissions of an enterprise do not exceed the quota, the income derived from the sale of carbon emission rights will be $P_{A}, P_{A}=p\left(D-D_{A}\right)$. When the enterprise emissions are excess, it will be required to purchase the carbon emission right, and the cost is $P_{N}, P_{N}=p\left(D_{N}-D\right)$. Assuming that enterprises can meet their emissions targets by purchasing carbon credits from others, local governments will not have to bear the losses $(V)$ because the total amount of carbon quotas in the whole society is stable. The income function of local government and enterprises under different strategies can be obtained in Table 2 ( $\mathrm{x}$ and y are the probability).

Table 2. The game payment matrix of local government and enterprises (consideration of carbon emission trading)

\begin{tabular}{l|l|c|c}
\hline \multirow{2}{*}{ Strategies } & \multicolumn{2}{|c}{ The enterprise } \\
\cline { 3 - 4 } & & $\begin{array}{c}\text { A-implementing } \\
\text { EPP }(\mathbf{y})\end{array}$ & $\begin{array}{c}\text { N-not implementing } \\
\text { EPP (1-y) }\end{array}$ \\
\hline \multirow{3}{*}{ Local government } & H-Strict supervision (x) & $P_{g}-C_{g h}, a D_{A}+P_{c}+P_{A}$ & $-C_{g h}, a D_{N}-P_{N}$ \\
\cline { 2 - 4 } & L-Lax regulation (1-x) & $P_{g}-C_{g l}, a D_{A}+P_{c}+P_{A}$ & $-C_{g l}-V, a D_{N}$ \\
\hline
\end{tabular}

It can be seen that local government's expected benefits $\left(\pi_{g}(H)\right.$ and $\left.\pi_{g}(L)\right)$ of strategy $\mathrm{H}$ and L (i.e., strict supervision and lax supervision) and the average expected groups earnings $\left(\bar{U}_{g}\right)$ of local government are as below (Eqs. 1-3):

$$
\begin{gathered}
\pi_{g}(H)=y \pi_{g}(H, A)+(1-y) \pi_{g}(H, N)=y\left(P_{g}-F+V\right)+F-V-C_{g h} \\
\pi_{g}(L)=y \pi_{g}(L, A)+(1-y) \pi_{g}(L, N)=y\left(P_{g}+V\right)-V-C_{g l}
\end{gathered}
$$




$$
\bar{U}_{g}=x \pi_{g}(H)+(1-x) \pi_{g}(L)
$$

So the replicated dynamic equation for the local government is (Eq. 4):

$$
F(x)=d x / d t=x\left[\pi_{g}(H)-\bar{U}_{g}\right]=x(1-x)(-V y+V-\Delta C)
$$

Similarly, the enterprises' expected benefits $\left(\pi_{c}(A)\right.$ and $\left.\pi_{c}(N)\right)$ of strategy A and $\mathrm{N}$ (i.e., implement EPP or not) and the average expected groups earnings $\left(\bar{U}_{c}\right)$ of enterprise are (Eqs. 5-7):

$$
\begin{gathered}
\pi_{c}(A)=x \pi_{c}(H, A)+(1-y) \pi_{c}(L, A)=a D_{A}+P_{c}+P_{A} \\
\pi_{c}(N)=x \pi_{c}(H, N)+(1-x) \pi_{c}(L, N)=-P_{N} x+a D_{N} \\
\bar{U}_{c}=y \pi_{c}(A)+(1-y) \pi_{c}(N)
\end{gathered}
$$

The replicated dynamic equation for the enterprise is $(E q .8)$ :

$$
F(y)=d y / d t=y\left[\pi_{c}(a)-\bar{U}_{c}\right]=y(1-y)\left(P_{N} x+P_{c}+P_{A}-a \Delta D\right)
$$

Set $F(x)=0$, two possible stable state points can be obtained: $x_{1}=0, x_{2}=1$ and (Eq9)

$$
y^{*}=1-\Delta C / V
$$

Set $F(y)=0$, two possible stable state points also can be obtained: $y_{1}=0, y_{2}=1$ and (Eq. 10)

$$
x^{*}=\left(a \Delta D-P_{c}-P_{A}\right) / P_{N}
$$

So, $(0,0),(1,0),(0,1),(1,1)$ are the equilibrium points of evolutionary game system. When $V>\Delta C, 0<y^{*}<1$; When $0<a \Delta D-P_{c}-P_{A}<P_{N}, 0<x^{*}<1$; Then $\left(x^{*}, y^{*}\right)$ is also the equilibrium point. Therefore, there are totally five equilibrium points.

\section{Model stability analysis and evolution paths}

This part will analyze Jacobian matrix's determinant and trace of the equilibrium points.

Four propositions (1)-(4) are given:

(1) When $a \Delta D<P_{c}+P_{A}$, the evolutionary stability strategy of game system is $(L, A)$; 
(2) When $R<\Delta C, \alpha \Delta D-P_{c}>0$, the evolutionary stability strategy of game system is $(L, N)$;

(3) When $R>\Delta C, \alpha \Delta D>R+P_{c}$, the evolutionary stability strategy of game system is $(H, N)$;

(4) When $R>\Delta C, 0<\alpha \Delta D-P_{c}<R$, there is no evolutionary stability strategy in the game system.

Below is the prove process:

In the carbon trade situation, the Jacobian matrix of this game system is (Eq. 11):

$$
\left[\begin{array}{cc}
(1-2 x)(-V y+V-\Delta C) & -V x(1-x) \\
P_{N} y(1-y) & (1-2 y)\left(P_{N} x+P_{c}+P_{A}-a \Delta D\right)
\end{array}\right]
$$

Jacobian matrix's determinant and trace of every equilibrium point can be shown in Table 3.

Table 3. Jacobian matrix's determinant and trace of every equilibrium point

\begin{tabular}{c|c|c}
\hline Equilibrium point & $\operatorname{det} J$ & $\operatorname{tr} J$ \\
\hline$(0,0)$ & $(V-\Delta C)\left(P_{c}+P_{A}-a \Delta D\right)$ & $V-\Delta C+P_{c}+P_{A}-a \Delta D$ \\
$(0,1)$ & $\Delta C\left(P_{c}+P_{A}-a \Delta D\right)$ & $a \Delta D-P_{c}-P_{A}-\Delta C$ \\
$(1,0)$ & $(\Delta C-V)\left(P_{N} x+P_{c}+P_{A}-a \Delta D\right)$ & $\Delta C-V+P_{N}+P_{c}+P_{A}-a \Delta D$ \\
$(1,1)$ & $\Delta C\left(a \Delta D-P_{N}-P_{c}-P_{A}\right)$ & $\Delta C+a \Delta D-P_{N}-P_{c}-P_{A}$ \\
$\left(x^{*}, y^{*}\right)$ & $\begin{array}{l}\Delta C(\Delta C-V)\left({ }_{N} x+P_{c}+P_{A}-a \Delta D\right)\left(P_{c}\right. \\
\left.+P_{A}-a \Delta D\right) / V P_{N}\end{array}$ \\
\hline
\end{tabular}

There are six situations (a)-(f) for the parameters in this game:

(a) $V<\Delta C, a \Delta D<P_{c}+P_{A}$;

(b) $V<\Delta C, P_{c}+P_{A}<a \Delta D<P_{c}+P_{A}+P_{N}$;

(c) $V<\Delta C, a \Delta D>P_{c}+P_{A}+P_{N}$;

(d) $V>\Delta C, a \Delta D<P_{c}+P_{A}$;

(e) $V>\Delta C, P_{c}+P_{A}<a \Delta D<P_{c}+P_{A}+P_{N}$;

(f) $V>\Delta C, a \Delta D>P_{c}+P_{A}+P_{N}$.

Analyzing the Jacobian matrix of every equilibrium point in each situation, local stability of equilibrium point in each situation can be shown in Table 4 .

Based on Table 4, the system evolution phase diagram of each situation in Figure 1 can be shown as Figure 1, thus the propositions (1)-(4) can be proved. 


$$
-706-
$$

Table 4. Local stability of equilibrium point in each situation (considering carbon trading)

\begin{tabular}{|c|c|c|c|c|c|c|}
\hline \multirow{2}{*}{$\begin{array}{c}\text { Equilibrium } \\
\text { point }\end{array}$} & \multicolumn{3}{|c|}{ Situation No. 1} & \multicolumn{3}{|c|}{ Situation No. 2} \\
\hline & $\operatorname{det} J$ & $\operatorname{tr} j$ & Stability & $\operatorname{det} J$ & $\operatorname{tr} j$ & Stability \\
\hline$(0,0)$ & - & Uncertain & Saddle point & + & - & ESS \\
\hline$(0,1)$ & + & - & ESS & - & Uncertain & Saddle point \\
\hline$(1,0)$ & + & + & Unstable & - & Uncertain & Saddle point \\
\hline$(1,1)$ & - & Uncertain & Saddle point & + & + & Unstable \\
\hline$\left(x^{*}, y^{*}\right)$ & \multicolumn{3}{|c|}{ Unequilibrium point } & \multicolumn{3}{|c|}{ Unequilibrium point } \\
\hline \multirow{2}{*}{$\begin{array}{c}\text { Equilibrium } \\
\text { point }\end{array}$} & \multicolumn{3}{|c|}{ Situation No.3 } & \multicolumn{3}{|c|}{ Situation No.4 } \\
\hline & $\operatorname{det} J$ & $\operatorname{tr} j$ & Stability & $\operatorname{det} J$ & $\operatorname{tr} j$ & Stability \\
\hline$(0,0)$ & + & - & ESS & + & + & Unstable \\
\hline$(0,1)$ & - & - & Saddle point & + & - & ESS \\
\hline$(1,0)$ & + & + & Unstable & - & + & Saddle point \\
\hline \multirow{2}{*}{$\begin{array}{c}(1,1) \\
\left(x^{*}, y^{*}\right)\end{array}$} & - & + & Saddle point & - & - & Saddle point \\
\hline & \multicolumn{3}{|c|}{ Unequilibrium point } & \multicolumn{3}{|c|}{ Unequilibrium point } \\
\hline \multirow{2}{*}{$\begin{array}{c}\text { Equilibrium } \\
\text { point }\end{array}$} & \multicolumn{3}{|c|}{ Situation No.5 } & \multicolumn{3}{|c|}{ Situation No.6 } \\
\hline & $\operatorname{det} J$ & $\operatorname{tr} j$ & Stability & $\operatorname{det} J$ & $\operatorname{tr} j$ & Stability \\
\hline$(0,0)$ & - & Uncertain & Saddle point & - & - & Saddle point \\
\hline$(0,1)$ & - & Uncertain & Saddle point & - & + & Saddle point \\
\hline$(1,0)$ & - & Uncertain & Saddle point & + & - & ESS \\
\hline$(1,1)$ & - & Uncertain & Saddle point & + & + & Unstable \\
\hline$\left(x^{*}, y^{*}\right)$ & - & 0 & & \multicolumn{3}{|c|}{ Unequilibrium point } \\
\hline
\end{tabular}

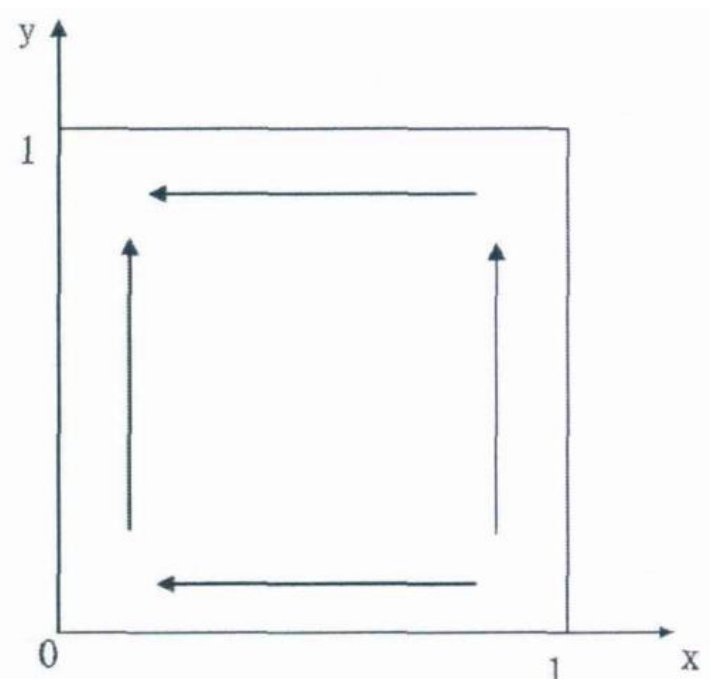

Situation No.1

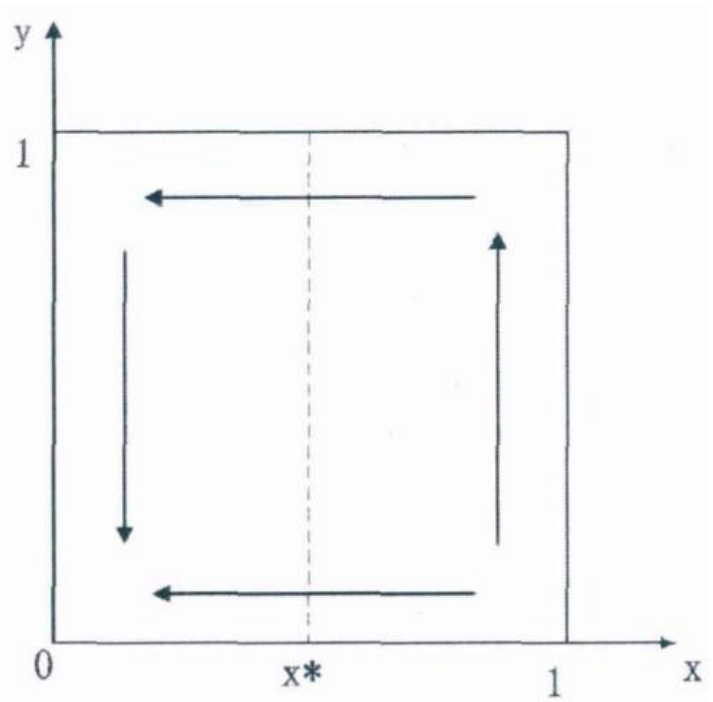

Situation No.2 


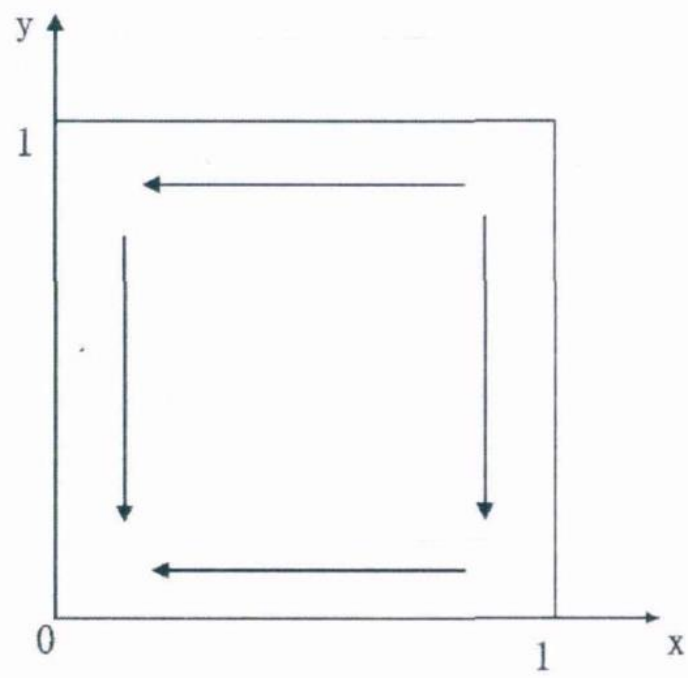

Situation No.3

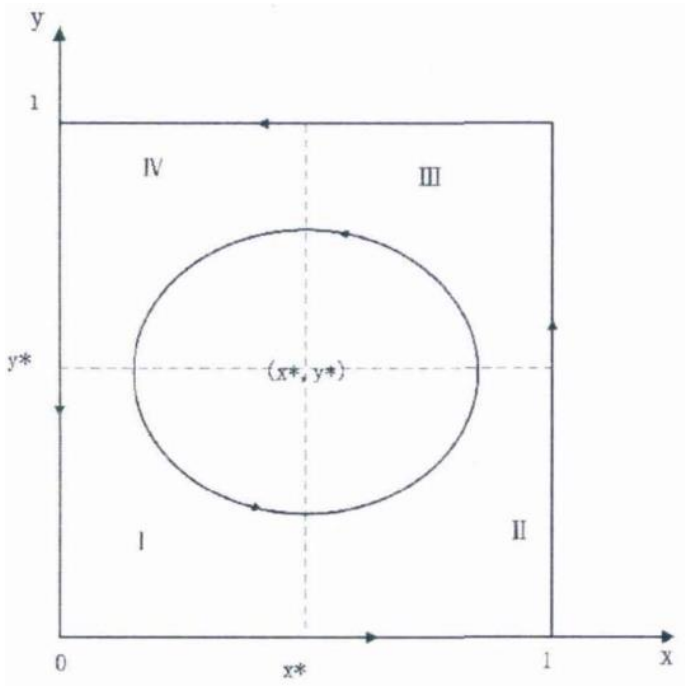

Situation No.5

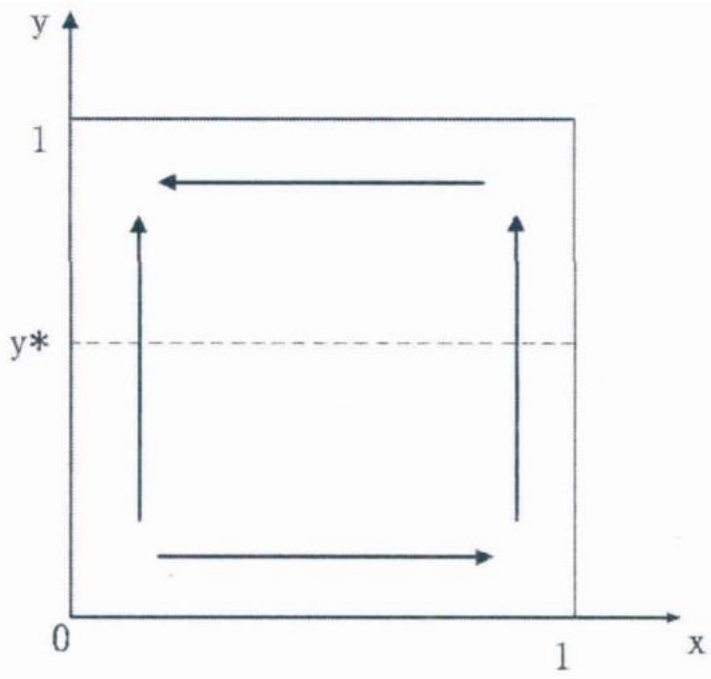

Situation No.4

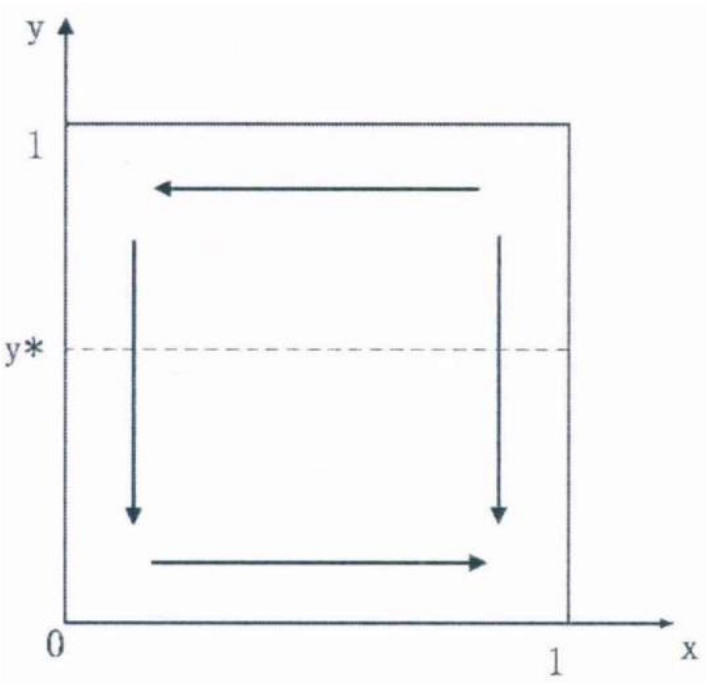

Situation No.6

Figure 1. The system evolution phase diagram in each situation

\section{Results}

\section{Model result analysis}

The following conclusions can be summarized through the model construction and system evolution phase diagram.

(1) When $a \Delta D<P_{c}+P_{A}$, the evolutionary stability strategy of game system is $\{L, A\}$. Point $(0,1)$ is the only evolutionary stable point, no matter what the initial state is, the system always converges to $(0,1)$. This suggests that the local government can only have the best interest by opting for lax regulation. The evolution of the system will converge to strategy $\{L, A\}$. This is the stable state the local government would like to see under the carbon emission trading mechanism, namely, under the conditions of lax supervision, the enterprises can consciously implement EPP.

(2) When $V<\Delta C, P_{c}+P_{A}<a \Delta D<P_{c}+P_{A}+P_{N}$, the evolutionary stability strategy of game system is $\{L, N\}$. Point $(0,0)$ is the only evolutionary stable point, no matter what 
the initial state is, the system always converges to $(0,0)$. It is not willing to be seen by local government. The government can reduce $a \Delta D$ or increase $P_{c}, P_{A}, P_{N}$ to promote the two stages gradually to the situation (1). The concrete measures include properly lower power price $e$, improve the carbon trading price $p$, increase earnings to enterprise by intensifying propaganda and support to the enterprise implementing EPP.

(3) When $V>\Delta C, 0<a \Delta D-P_{c}-P_{A}<P_{N}$, there is no evolutionary stabilization strategy in game system. The evolution trend of the system depends on the initial state of the game between the two groups in Figure 1.

(4) When $V>\Delta C, a \Delta D>P_{c}+P_{A}+P_{N}$, the evolutionary stability strategy of game system is $\{H, N\}$. Point $(1,0)$ is the only evolutionary stable point, no matter what the initial state is, the system always converges to $(1,0)$. This moment the loss to local government in lax supervision is more than the regulatory scrutiny when strict supervision, but the earnings to the enterprise by excessive emissions outstrip the benefits of observing carbon emissions constraints.

\section{Parameter sensitivity analysis result}

This part will use Matlab software to simulate the impact on the stability of game equilibrium results from some important parameters in the game model.

First the six variables $V, \Delta C, P_{N}, P_{c}, P_{A}, \Delta D$ in the replicated dynamic equation (Eq.4) and Equation 8 are set as constants, then the impact on the probability y of enterprises implementing EPP from the probability $\mathrm{x}$ of government regulation is analyzed.

(1) When $x=0.2$, replicated dynamic equation is simulated in Matlab, and the evolution result graph of y taking different values is shown in Figure $2 a$.

(2) When $x=0.8$, replicated dynamic equation is simulated in Matlab, and the evolution result graph of y taking different values is shown in Figure $2 b$.

Figure 2 shows that government's regulatory attitude will have a great impact on the game result. When the government supervises with low probability, the probability of enterprise implementing EPP will gradually decrease and eventually converge to 0 . When the government regulates with high probability, the probability of enterprise implementing EPP will gradually increase and eventually converge to 1.

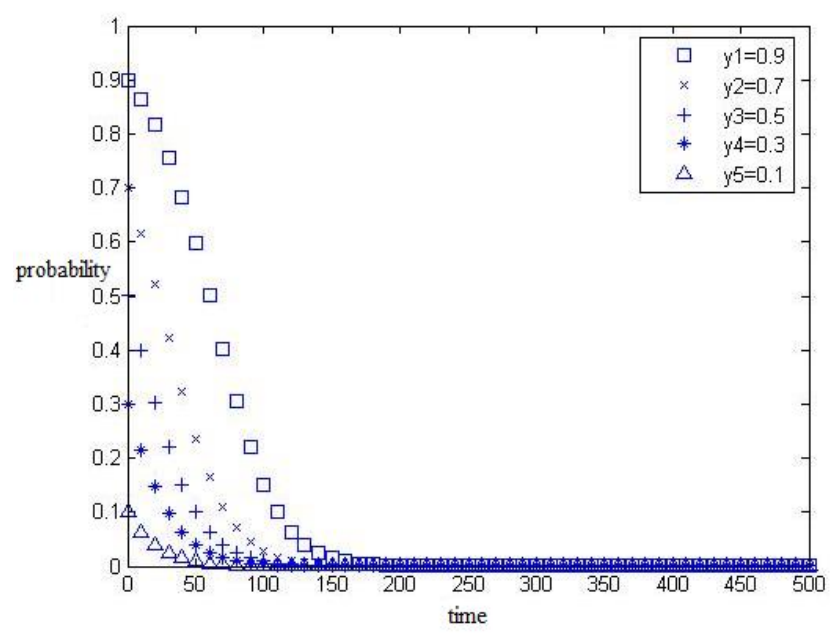




$$
-709-
$$

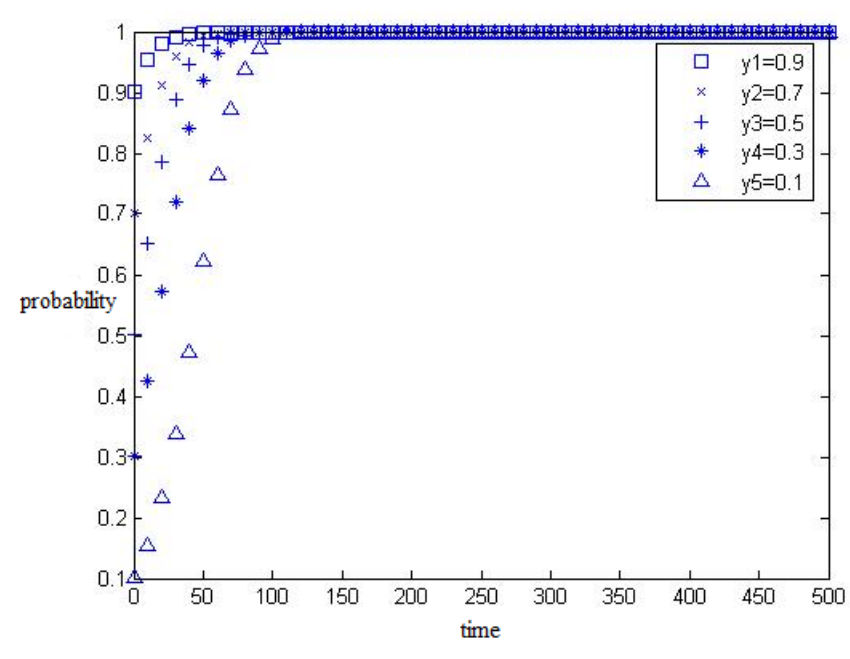

b

Figure 2. Evolution result graph of y taking different values when $x=0.2$ and $x=0.8$

In the second part the impact on the probability y of enterprises implement EPP from the fines $\mathrm{F}$ on excessive carbon emissions will be analyzed, and $\mathrm{x}=0.5$ will be set to weaken the impact of government supervision on enterprises.

(1) When $F=0.2$, replicated dynamic equation is simulated in Matlab, and the evolution result graph of y taking different values is shown in Figure $3 a$.

(2) When $F=0.5$, replicated dynamic equation is simulated in Matlab, and the evolution result graph of y taking different values is shown in Figure $3 b$.

Figure 3 indicates the punishment strength of the government has a positive influence on the game balance. If the government chooses a large scale of punishments, it will encourage enterprises to actively implement EPP, so that the game equilibrium will evolve towards the ideal direction. If the amount of penalty for not implementing EPP is very low, it cannot affect enterprises effectively.

In the last part the impact on the probability $\mathrm{x}$ of local government's supervision from $P_{g}$ (profit of government when carbon emissions are within the quota) is analyzed, and $y=0.5$ is set to weaken the impact of enterprises' decision on implementing EPP.

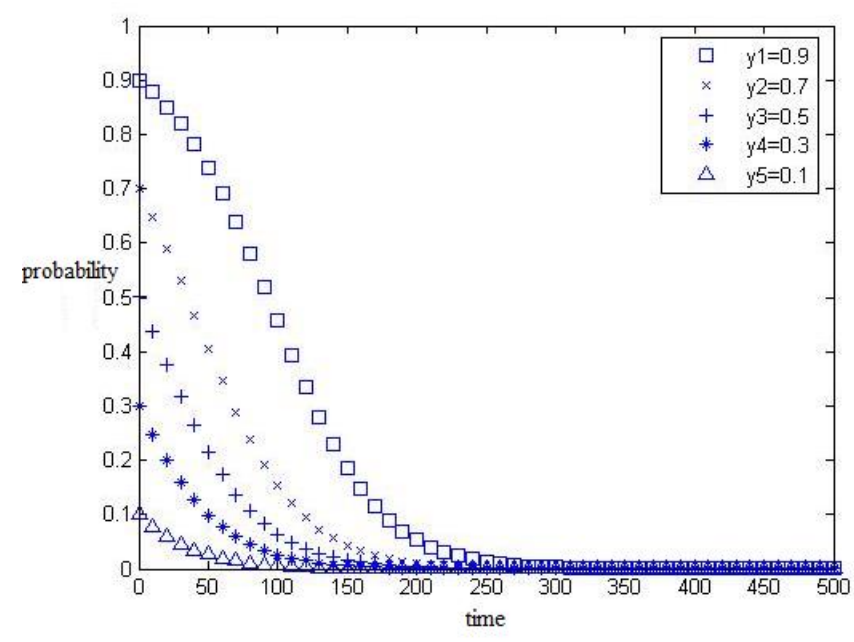

$\mathbf{a}$ 


$$
-710-
$$

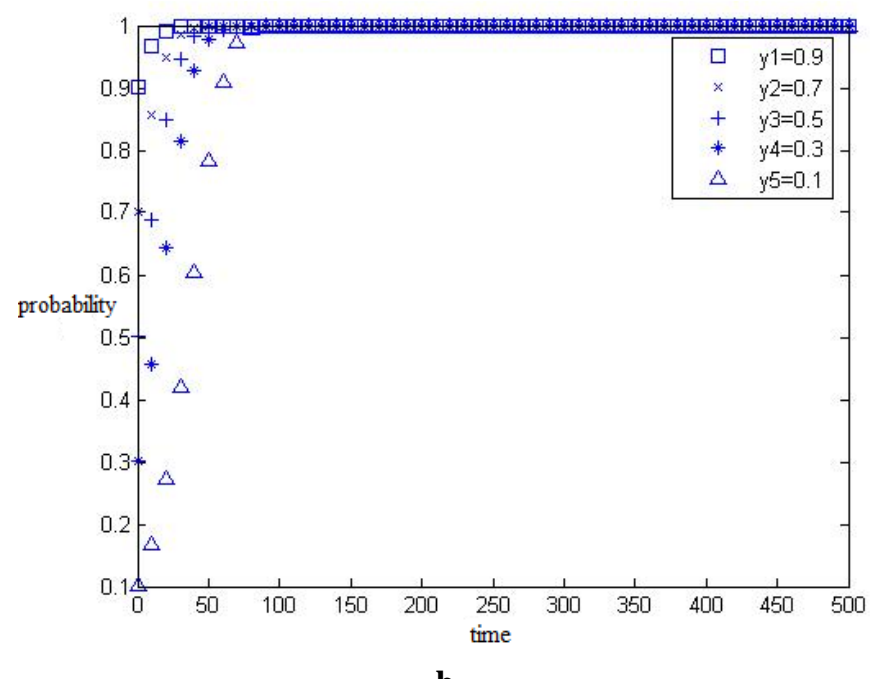

b

Figure 3. Evolution result graph of y taking different values when $F=0.2$ and $F=0.5$

(1) When $P_{g}=0.1$, replicated dynamic equation is simulated in Matlab, and the evolution result graph of y taking different values is shown in Figure $4 a$.

(2) When $P_{g}=0.6$, replicated dynamic equation is simulated in Matlab, and the evolution result graph of y taking different values is shown in Figure $4 b$.

When social positive reward value is high, regardless of the initial probability $\mathrm{x}$ of decision on supervision, after a long period $\mathrm{x}$ will gradually increase and in the long term converges to 1 . This indicates that when the public has a strong awareness of environmental protection and energy conservation, and recognizes the importance of implementing EPP, the public will urge government to actively regulate enterprises that do not implement EPP, at last promoting the development of EPP.

\section{Calculation example analysis}

To verify that the model results are valid or not, this part will use a calculation example to analyze the influence on the game equilibrium from government's rewards and penalties to the enterprise implementing EPP. A case of EPP projects in Hebei Province, China is taken as sample. In this part, three kind of original data are collected in different ways:

(1) The basic information and data of the EPP project, such as project name, investment amount, annual power saving, annual carbon emission, equipment life and other information come from Hebei Demand Side Center (HBDSM).

(2) The common parameters, such as electricity market price, carbon price, rate of interest, rate of depreciation and other data are referred to recent data released by authorities.

(3) To other data needed in this calculation of the EPP project, such as gains and losses for the government when implementing EPP or not, the cost of government regulation, the carbon emission quota that the enterprise is allocated, and other data which are not easy to get, these data are assumed at a reasonable level. 


$$
-711-
$$

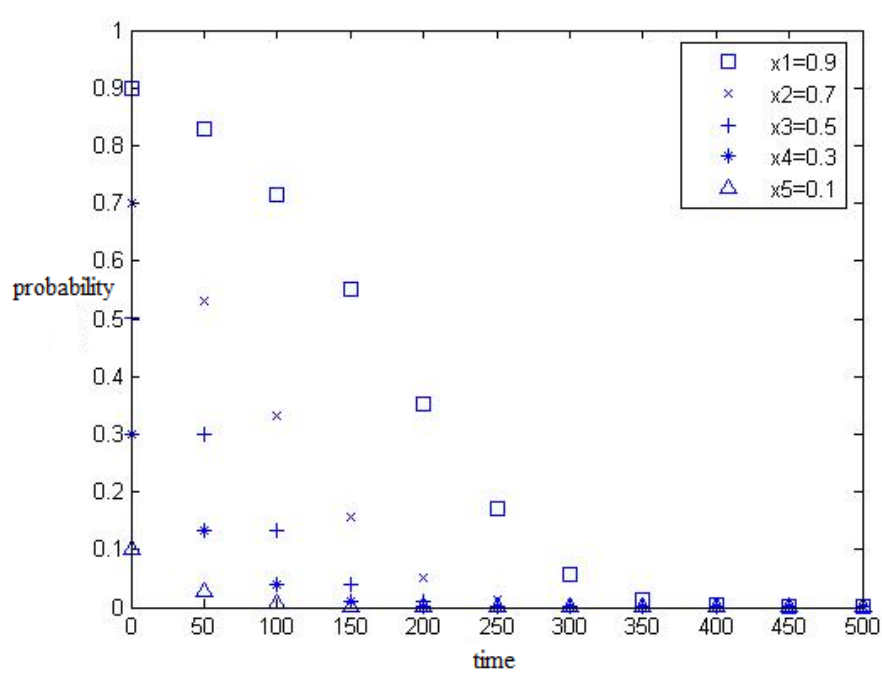

$\mathbf{a}$

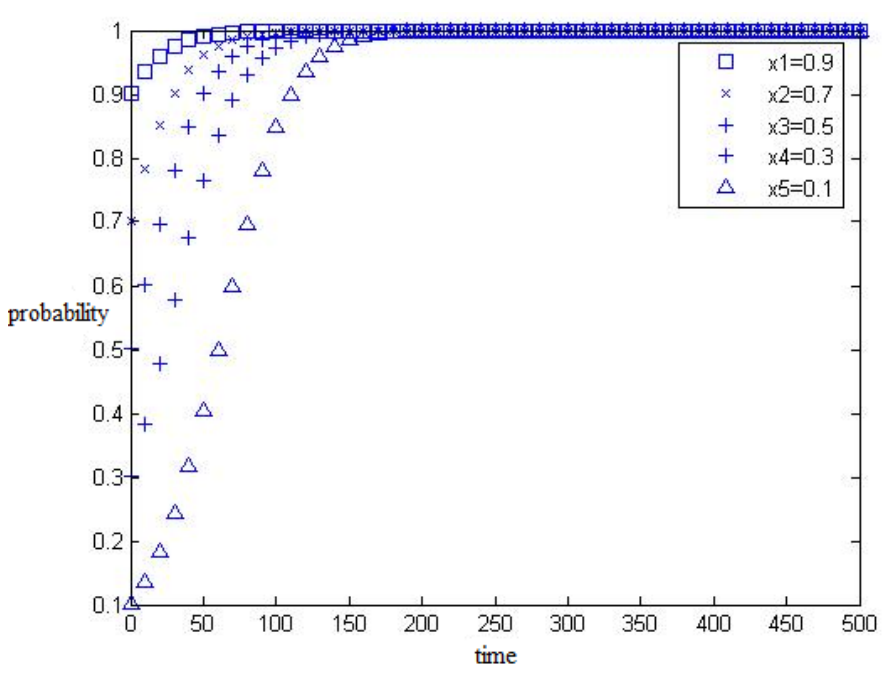

b

Figure 4. Evolution result graph of $x$ taking different values when $P_{g}=0.1$ and $P_{g}=0.6$

Table 4 shows some important parameters in this calculation example.

Table 4. The values of main parameters in the calculation example

\begin{tabular}{c|c|c}
\hline Parameter & Unit & Value \\
\hline Annual power saving $(\mathrm{Q})$ & $\mathrm{kWh}$ & $6.325^{*} 10^{5}$ \\
$c_{0}$ & dollar/ kWh & 0.042 \\
$e$ & dollar $/ \mathrm{kWh}$ & 0.057 \\
$D$ & $\mathrm{~kg}$ & $4,000,000$ \\
$C_{g H}$ & dollar & 2,800 \\
$C_{g L}$ & dollar & 5,700 \\
Average life of equipment of EPP project (T) & year & 18 \\
Annual loan rate (r) & - & $5.6 \%$ \\
\hline
\end{tabular}


Assuming the government will reward enterprises according to the power saved by EPP, and the size of the reward is a certain proportion $\left(r_{c}\right)$ of the power saved.

The other parameter is $r_{p}$, and the government will punish enterprises according to carbon emission beyond the quota, namely, the size of the penalty is a certain proportion $\left(r_{p}\right)$ of carbon emission beyond the quota.

The impact on the game equilibrium and evolution direction from government's different strategies (mainly $r_{c}$ and $r_{p}$ ) is analyzed. Because the data in this study are complex and there are multifarious index operation, so vc++ (version 6.0) is used to construct a program to achieve the solution of this case study, and the results are shown in Table 5.

Table 5. The strategy probability and expected profit $U$ of government and enterprise under different $r_{c}$ and $r_{p}$

\begin{tabular}{c|c|c|c|c|c}
\hline$r_{c}$ & $r_{p}$ & $\mathbf{x}$ & $\mathbf{y}$ & $\overline{U_{g}}$ (USD) & $\overline{U_{c}}$ (USD) \\
\hline 0.1 & 0.1 & 0.4839 & 0.3518 & 3385 & 51571 \\
0.11 & 0.1 & 0.4864 & 0.3391 & 3443 & 51462 \\
0.12 & 0.1 & 0.4092 & 0.3273 & 3496 & 51361 \\
0.13 & 0.1 & 0.4929 & 0.3163 & 3546 & 51267 \\
0.14 & 0.1 & 0.4968 & 0.3060 & 3593 & 51097 \\
0.15 & 0.1 & 0.5075 & 0.2963 & 3637 & 51097 \\
0.1 & 0.11 & 0.4554 & 0.2723 & 3385 & 51677 \\
0.1 & 0.12 & 0.4301 & 0.2016 & 5512 & 51771 \\
0.1 & 0.13 & 0.4074 & 0.1383 & 6408 & 51855 \\
0.1 & 0.14 & 0.3870 & 0.0814 & 7213 & 51931 \\
0.1 & 0.15 & 0.3686 & 0.0299 & 7943 & 51999 \\
0.11 & 0.11 & 0.4399 & 0.2630 & 4527 & 51571 \\
0.12 & 0.12 & 0.4032 & 0.1890 & 5479 & 51571 \\
0.13 & 0.13 & 0.3722 & 0.1263 & 6284 & 51571 \\
0.14 & 0.14 & 0.3456 & 0.0727 & 6974 & 51571 \\
0.15 & 0.15 & 0.3226 & 0.0261 & 7572 & 51571 \\
\hline
\end{tabular}

According to Table 5, when the government adopts the strategy of high reward and light penalty (increase the value of $r_{c}$ and keep $r_{p}$ steady), the value of $\mathrm{x}$ raises and the value of y decreases progressively, the government's expected profit raises and the enterprise's decreases progressively; When the government adopts the strategy of light reward and heavy penalty (keep $r_{c}$ steady, increase the value of $r_{p}$ ), both $\mathrm{x}$ and $\mathrm{y}$ decreases progressively, both expected profit of government and enterprise raises progressively; When the government adopts the strategy of high reward and heavy penalty (increase the value of $r_{c}$ and $r_{p}$ ), both $\mathrm{x}$ and $\mathrm{y}$ decreases progressively, the government's expected profit raises and the enterprise's keeps steady. Combined with the expectation of system evolution direction $(1,1) /$ strategy $\{\mathrm{H}, \mathrm{A}\}$, compared the three different kinds of incentive strategy, strategy \{light reward, heavy penalty $\}$ and strategy 


$$
-713-
$$

\{high reward, heavy penalty\} are both dominant strategies. While the government and enterprise have a higher expected profit in strategy \{high reward, heavy penalty .

\section{Discussion}

In this paper three important contents are put forward:

Firstly, an evolutionary game model between government and enterprise on implementing EPP considering carbon emission right trading is proposed, and the model's stability and evolution paths are analyzed.

Secondly, Matlab software is used to simulate the impact from sensitivity of some important parameters (the probability $\mathrm{x}$ of government regulation, fines $\mathrm{F}$ on excessive carbon emissions, and the profit of government when carbon emissions are within the quota).

Finally, a calculation example is carried out to analyze the influence on the game equilibrium from government's rewards and penalties. And vc++ is used to write a program (seen Appendix) to achieve the solution of this case study.

Compared to literatures (Du et al., 2015; Xiao et al., 2018) about the game study of low-carbon investment, low-carbon investment is translated into implementation of EPP, and specific research conclusions and specific recommendations are given; Compared to literatures (Wang et al., 2018; Zhou and Ye, 2018) about the game study of carbon emission, besides the carbon emission energy savings are considered as one of the benefits of implementing EPP; Compared to literatures ( $\mathrm{Zu}$ et al., 2018) about the study of differential game, evolutionary game analysis is focused on and the model's stability and evolution paths are analyzed; Compared to literatures (Gu et al., 2017; Wu et al., 2017) about the evolutionary game study of low carbon, the sensitivity of some important parameters is simulated and the influence on the game equilibrium from government's rewards and penalties by a calculation example are analyzed, which is consistent with the evolutionary model's conclusion.

\section{Conclusion and suggestion}

\section{Conclusion}

(1) The evolutionary game process and stability strategy of local governments and power generation enterprises are systematically analyzed under the carbon emission trading mechanism. The research found that when the expected increase earnings from enterprise's excess emissions are less than the sum of indirect profit from the carbon emission constraint and the sale of surplus carbon allowance income, excess emissions are not tempting for enterprises implementing EEP, the strategy of enterprises implementing EEP will tend to not excessive emissions, and local governments will choose a strategy of loose regulation. When the loss caused by loose local government supervision exceeds the extra cost of the strict supervision, and the expected increased earnings in excess emission from enterprises implementing EEP is greater than the sum of the income from the carbon emission constraint and the sales of the carbon allowance, and less than the sum of income from the carbon emission constrain, income from the sale of carbon allowances and purchase of carbon allowances in excess emissions, the game between local governments and enterprises implementing EEP shows a periodic behavior pattern. 
(2) The different influences of the typical variables on the evolution process of the game are discussed through simulation. It is found that whether the regulatory action chosen by government is positive has a significant impact on the decision-making of the enterprise. The appropriate reward and punishment mechanism of the government will guide the enterprises to choose to product with a low-carbon production methods. And the public's low carbon awareness will also have a positive impact on the government's choice of regulatory actions.

\section{Suggestion}

The impact of different initial states and different factors on enterprises emission reduction strategies was analyzed, and policy recommendations were made for local governments. This paper proposes that local governments can promote carbon emissions from enterprises implementing EEP within carbon allowance. The measures that can be taken are to increase incentives for actively complying with carbonconstrained emission reduction enterprises, to appropriately increase the carbon emission trading price of the carbon market, to reduce the cost difference between strict and loose local government supervision, and to strengthen the supervision of the government by public. In the end, the control objectives of the total amount of social carbon emissions will be achieved.

Acknowledgements. This paper is a periodic result of "humanities and social science project of year 2018 for high schools in Jiangxi province, China" (No. TQ18108).

\section{REFERENCES}

[1] Cao, J., Zhang, X. M., Zhou, G. G. (2016): Supply chain coordination with revenue-sharing contracts considering carbon emissions and governmental policy making. - Environmental Progress \& Sustainable Energy 35(2): 479-488.

[2] Du, S. F., Zhu, J., Jiao, H. F. et al. (2015): Game-theoretical analysis for supply chain with consumer preference to low carbon. - International Journal of Production Research 53(12): 3753-3768.

[3] Du, S. F., Hu, L., Wang, L. (2017): Low-carbon supply policies and supply chain performance with carbon concerned demand. - Annals of Operations Research 255(1-2): 569-590.

[4] Fan, H. M., Dong, G. S., Zhang, X. N. et al. (2012a): The research on the cooperation and coordination game in constructing low-carbon green oil port. - Low Carbon Economy 03(01). DOI: 10.4236/lce.2012.31003.

[5] Fan, H. M., Dong, G. S., Zhang, X. N. et al. (2012b): The cooperation and coordination game of constructing low-carbon green oil port. - Applied Mechanics and Materials 1802(178). https://doi.org/10.4028/www.scientific.net/AMM.178-181.1036.

[6] Fan, R. G., Dong, L. L. et al. (2017): Study on the optimal supervision strategy of government low-carbon subsidy and the corresponding efficiency and stability in the small-world network context. - Journal of Cleaner Production 168: 536-550.

[7] Gu, L. Q., Xi, L. L., Wen, S. L. (2017): Exploration on the low-carbon strategy based on the evolutionary game between the government and highway logistics enterprises. - Agro Food Industry Hi-Tech 28(1): 1796-1800.

[8] He, L. F., Zhang, X., Wang, Q. P. et al. (2018): Game theoretic analysis of supply chain based on mean-variance approach under cap-and-trade policy. - Advances in Production Engineering \& Management 13(3): 333-344. 


$$
-715-
$$

[9] Li, H., Wang, C. X., Xu, L. et al. (2017): Pricing, carbon emission reduction, collection decision, and coordination in a low-carbon closed-loop supply chain. - Journal of Renewable and Sustainable Energy 9(6). https://doi.org/10.1063/1.4991668.

[10] Liu, B., Li, T., Tsai, S. B. (2017): Low carbon strategy analysis of competing supply chains with different power structures. - Sustainability 9(5): 1-21.

[11] Luo, Z., Chen, X., Wang, X. J. (2016): The role of co-opetition in low carbon manufacturing. - European Journal of Operational Research 253(2): 392-403.

[12] Meng, X. G., Yao, Z., Nie, J. J. et al. (2018): Low-carbon product selection with carbon tax and competition: effects of the power structure. - International Journal of Production Economics 200: 224-230.

[13] Rai, V., Beck, A. L. (2017): Play and learn: serious games in breaking informational barriers in residential solar energy adoption in the United States. - Energy Research \& Social Science 27: 70-77.

[14] Ratul, L. (2012): Evolutionary game theory: an exposition. - Indian Growth and Development Review 5(2): 203-213.

[15] Wang, J. M., Zhu, Y. P., Li, Y. K. (2015): EPP energy efficiency calculation and influencing factor analysis: cases in China. - Mathematical Problems in Engineering. http://dx.doi.org/10.1155/2015/986562.

[16] Wang, J. M., Ge, X. J. et al. (2016): Management index systems and energy efficiency diagnosis model for power plant: cases in China. - Mathematical Problems in Engineering. http://dx.doi.org/10.1155/2016/8159871.

[17] Wang, X. Y., Xue, M. G., Xing, L. (2018): Analysis of carbon emission reduction in a dual-channel supply chain with cap-and-trade regulation and low-carbon preference. Sustainability 10(3): 1-18.

[18] Wu, B., Liu, P. F., Xu, X. F. (2017): An evolutionary analysis of low-carbon strategies based on the government-enterprise game in the complex network context. - Journal of Cleaner Production 141: 168-179.

[19] Xiao, W. X., Du, G., Zhang, Y. Y. et al. (2018): Coordinated optimization of low-carbon product family and its manufacturing process design by a bilevel game-theoretic model. Journal of Cleaner Production 184: 754-773.

[20] Zhao, X. G., Wu, L., Li, A. (2017): Research on the efficiency of carbon trading market in China. - Renewable and Sustainable Energy Reviews 79: 1-8.

[21] Zhou, Y. J., Ye, X. (2018): Differential game model of joint emission reduction strategies and contract design in a dual-channel supply chain. - Journal of Cleaner Production 190: 592-607.

[22] Zhu, Y. P., Hu, Y., Zhang, F. L. (2017): Progressive IRP models for power resources including EPP. - Mathematical Problems in Engineering. https://doi.org/10.1155/2017/2520346.

[23] Zu, Y. F., Chen, L. H., Fan, Y. (2018): Research on low-carbon strategies in supply chain with environmental regulations based on differential game. - Journal of Cleaner Production 177: 527-546.

\section{APPENDIX}

The $v c++$ source program of the case study

(1)"stdafx.h"”

//stdafx.h: include file for standard system include files,

//or project specific include files that are used frequently, but

//are changed infrequently

\#if!defined(AFX_STDAFX_H_E360AElC_F4F9_47B6_9668_14C5744ABE57_INCLUDED_)

\#define AFX_STDAFX_H_E360AElC_F4F9_47B6_9668_14C5744ABE57_INCLUDED_ 


$$
-716-
$$

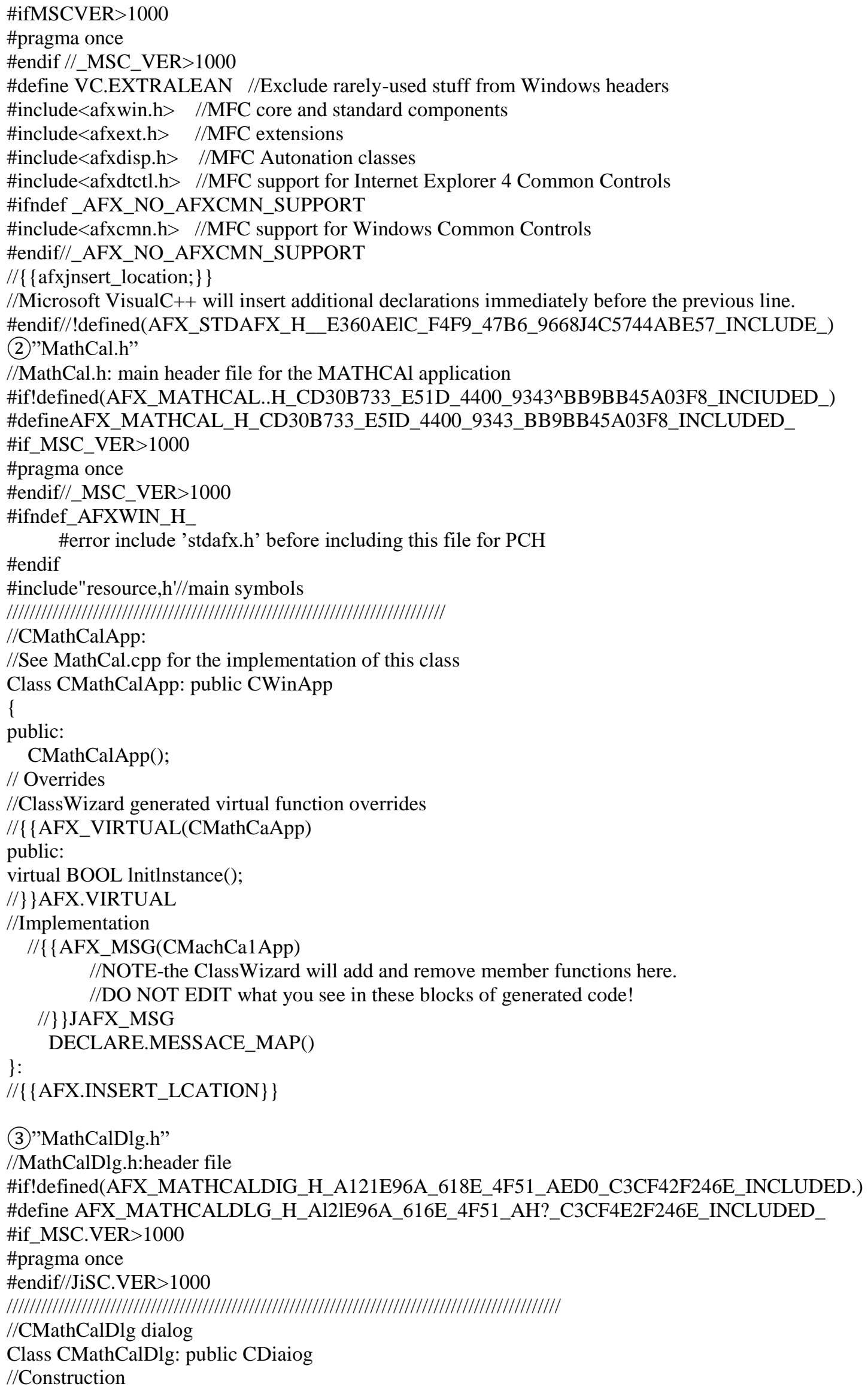


public:

\#CMathCalDlg(CWnd*pParent*NULL);//standard constructor

//DialogData

$/ /\{$ AFX.DATA(CMathCalDlg)

enua $\{$ IDD=IDO.MATHCAL.DIALOG $\}$;

CRichEditCtrln.edit.res;

Float $\mathrm{m}_{-} \mathrm{c} 0$;

Float $\mathrm{m} \_\mathrm{c} 1$;

Float $\mathrm{m}_{-} \mathrm{c} 2$;

Float $\mathrm{m}_{-} \mathrm{Cc}$;

Float $\mathrm{m} \_\mathrm{cp}$;

Float m_gsms;

Float m.lambda;

Float m.Q;

Float $\mathrm{m} \_\mathrm{dH}$;

Float m_qT;

Float $\mathrm{m} \_\mathrm{r}$;

Float $n_{-}$rc;

Float $\mathrm{m} \_$rg;

Float $n \_$rp;

Float $\mathrm{m}_{-} \mathrm{T}$ :

Float m.?;

Float m_p;

Float $\mathrm{m} . \mathrm{Sg}$;

//\}\}AFX_DATA

//Class Wizard generated virtual function overrides

$/ /(\{$ AFX.VIRIVAL(CMathCalDlg)

protected:

virtual void Do Data Exchange (CDataExchange*pDX);//DDX/DDVsupport

II) \}AFX_VIRTUAL

//Implementation

protected:

HICON m.hlcon;

//Generated message map functions

//\{ $\{$ AFX.MSG(CHathCalDlg)

Virtual BOOL OnlnitDialog();

afx.msg void OnSysCoauoand(UNIT nID,LPARAM IParam);

afx.msg voidOnPaintO;

afx.msg HCfRSOROnQueryDraglcon0;

afx.msg voidOnButtonCal0:

afx.msg voidOnButtonExit0;

//) \}AFX.MSG

DECLARE_MESSAGE_MAP()

private:

float m_pi_g_s;

float m_pi_g_ns;

float m_u_g;

float m_y;

float Bj_ijo_h;

float B_pi_l;

float $\mathrm{m} \_\mathrm{u} \_\mathrm{m}$;

float $m_{-} \mathrm{x}$ :

) :

$/ /\{$ AFX.INSERT.LOCATION) $\}$

//MicrosoftVisualC ${ }^{* *}$ wil linsert additional declarations immediately before the previous line, trendif//!defined(APX_MATHCALDLG.H Al21E96A.618E_4P51_AD0_C3CF4E2F246E UDED_) 


$$
-718 \text { - }
$$

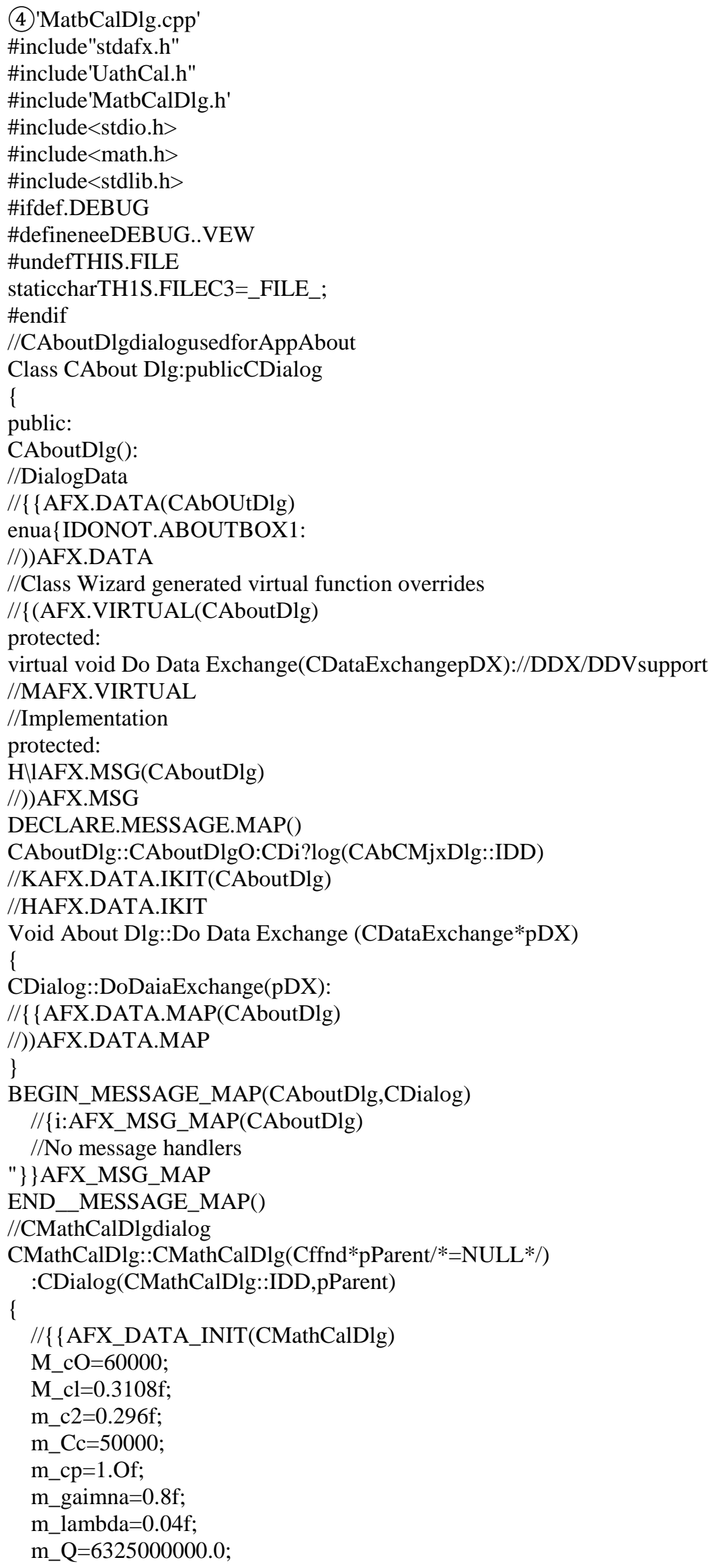




$$
-719 \text { - }
$$

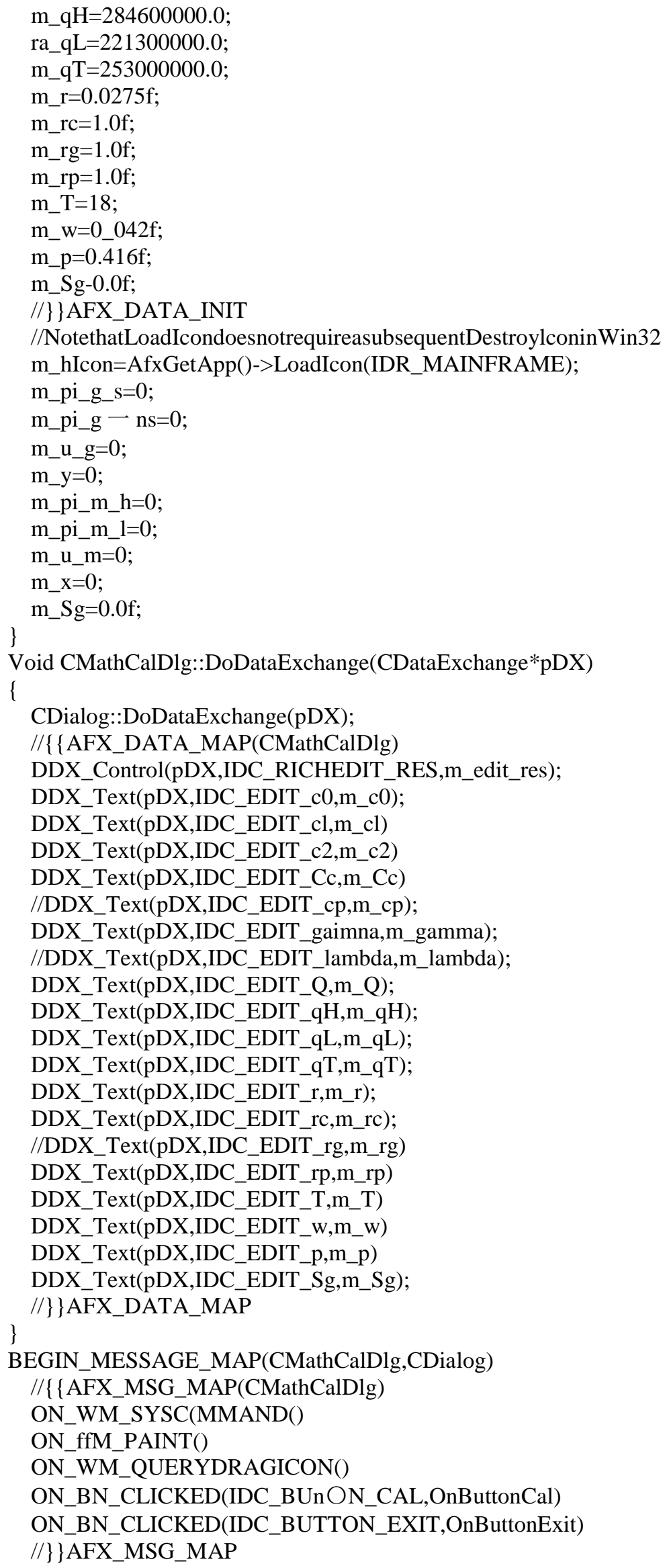




$$
-720 \text { - }
$$

END - MESSAGE_MAPO

//CMathCalDlgmessagehandlers

BOOLCMathCalDlg::OnInitDialog()

\{

CDialog::OnInitDialog();

//Add"About..."menu item to system menu.

//IDM_ABOUTBOX must be in the system command range.

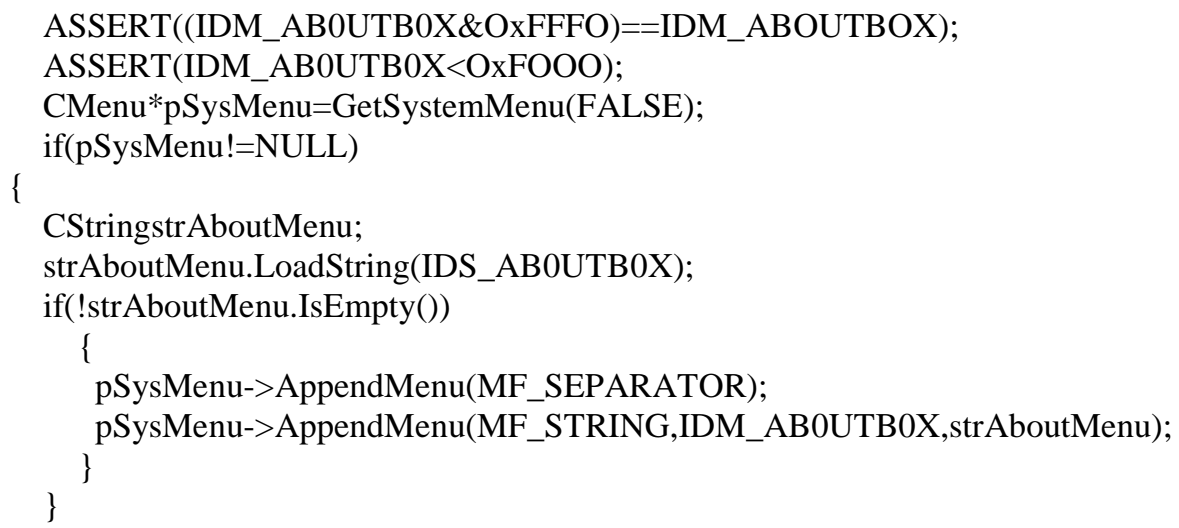


CPaintDCdc(this);//device context for painting

SendMessage(ffM_ICONERASEBKGND, (WPARAM)dc.GetSafeHdc(),0);

//Center icon in client rectangle

intcxlcon=GetSystemMetrics(SM_CXICON);

intcylcon=GetSystemMetrics(SM_CYIC0N);

CRectrect;

GetClientRect(\&rect);

int $x=($ rect.Width 0 -cxlcon +1$) / 2$;

inty $=($ rect.Height $0-$ cylcon +1$) / 2$;

//Drawtheicon

dc.Drawlcon(x, y, m- hicon);

\}

else

\{

CDialog::0nPaint0;

\}

\}

//The system calls this to obtain the cursor to display while the user drags

//the minimized window.

HCURSORCMathCalDlg::OnQueryDragIcon()

\{

return(HCURSOR)m_hIcon;

\}

Void CMathCalDlg::OnButtonCal0

\{

//TODO:Addyourcontrolnotificationhandlercodehere

UpdateData();

floatsum_ert=0;//surae"-rt

int $\mathrm{i}$;

for $\left(\mathrm{i}=1 ; \mathrm{i}<=\mathrm{m} \_\mathrm{T} ;++\mathrm{i}\right)$

\{

sum_ert+=1.0/exp(m_r*i);

\}

//CString msg;

$/ / \mathrm{m} \_\mathrm{y}$

m_y $=\left(\mathrm{m} \_\mathrm{Cc}-\mathrm{m} \_\mathrm{c} 0-\mathrm{sum} \_\right.$ert $\left.*\left(2 * \mathrm{~m} \_\mathrm{gamma}-\mathrm{m} \_r \mathrm{r}\right) *\left(\mathrm{~m} \_\mathrm{qT}-\mathrm{m} \_\mathrm{qL}\right)\right) /$

(sum_ert*(-m_rc*m_qH-(m_rp-m_rc)*m_qT+m_rp*m_qL));

//msg.Format("\%f, \%f, \%f", (m_Cc-m_c0-sum_ert*(m_cp+2*m_gamma-m_rg-

m_rp)*(m_qT-m_qL)),

//sum_ert*((m_rg-m_rc)*ra_qH-(2*m_rg'fm_rp-m_rc-m_cp $\left.)^{*} m \_q T-\left(m \_r g+r n \_r p+i n \_c p\right)^{\wedge} q L\right)$,

$\left./ / \mathrm{m} \_\mathrm{y}\right)$;

//MessageBox(msg);

$/ / \mathrm{m} \_\mathrm{x}$

$\mathrm{m} \_\mathrm{x}=\left(\mathrm{m} \_\mathrm{c} 2+\mathrm{m} \_\mathrm{w}+\mathrm{m} \_\mathrm{Sg}-\mathrm{m} \_\mathrm{c} 1\right) *\left(\mathrm{~m} \_\mathrm{qL}-\mathrm{m} \_\mathrm{qH}\right) /\left(\mathrm{m} \_\mathrm{rc} * \mathrm{~m} \_\mathrm{qH}+\left(\mathrm{m} \_\mathrm{rp}-\mathrm{m} \_\mathrm{rc}\right) \operatorname{stem} \_\mathrm{qT}-\mathrm{m} \_\mathrm{rp} * \mathrm{~m} \_\mathrm{qL}\right)$;

$/ / \mathrm{m} \_$pi_g_s

m_pi_g_s=m_y*sum_ert*((m-gamma-m-rc)*m - $\mathrm{qH} \_(\mathrm{m}-\mathrm{rp}-\mathrm{m}-\mathrm{rc}) * \mathrm{~m}-\mathrm{qT}+\left(\mathrm{m} \_\mathrm{rp}-\right.$

m_gamma)*m_qL)+

sum_ert*(m_rp-m_gamma)*(m_qT-m_qL)-m_Cc;

//m_pi_g_ns

m_pi_g_ns $=m \_y * s u m \_e r t * m \_g a m m a *\left(m \_q H-m \_q L\right)-m \_c O-s u m \_e r t * m \_g a i n m a *\left(m \_q T-n i \_q L\right)$;

$/ / \mathrm{m} \_$u_g

$\mathrm{m} \_\mathrm{u} \_\mathrm{g}=\mathrm{m}-\mathrm{x} * \mathrm{~m} \_\mathrm{pi}-\mathrm{g}$ - $\mathrm{s}+\left(1 \_\mathrm{m} \_\mathrm{x}\right) * \mathrm{~m} \_\mathrm{pi}-\mathrm{g}$ - ns;

$/ / \mathrm{m} \_$pi_m_h

m_pi_m_h $=m \_x * s u m \_e r t * m \_r c *\left(m \_q H-m \_q T\right)+s u m \_e r t *\left(\left(m \_p-m \_c 2-m \_w\right)+\right.$

$\left.\left(\mathrm{m} \_\mathrm{c} 2+\mathrm{m} \_\mathrm{w}+\mathrm{m} \_\mathrm{Sg}-\mathrm{m}-\mathrm{cl}\right\rangle * \mathrm{~m} \_\mathrm{qH}\right)$; 


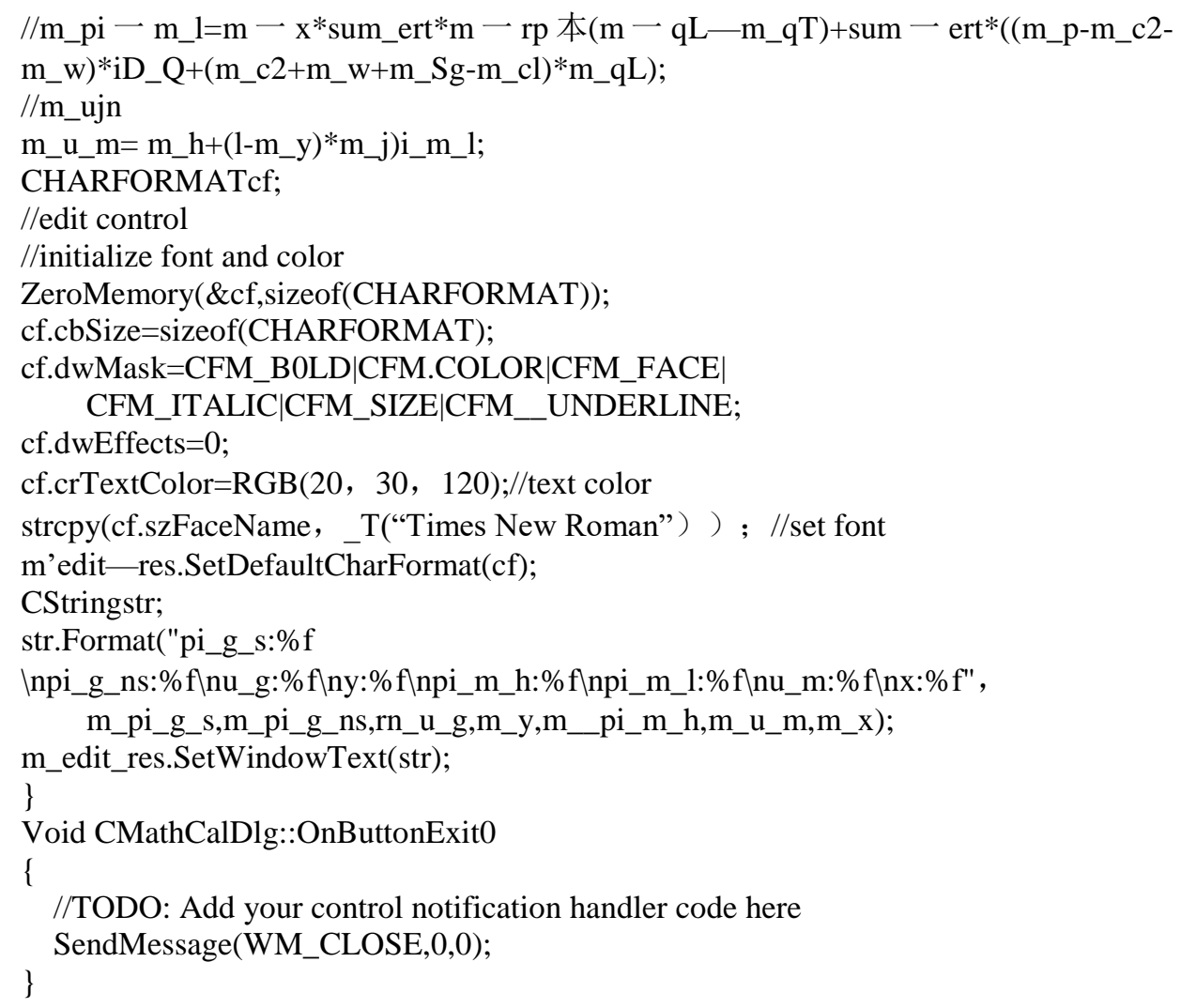

